Learning from Multimedia Materials: The Relative Impact of Individual Differences

\author{
Dr Michael Grimley
}

University of Canterbury, School of Education, Private Bag 4800, Christchurch, New Zealand. Email. Michael.Grimley@Canterbury.ac.nz 
Learning from Multimedia Materials: The Relative Impact of Individual Differences 


\begin{abstract}
This paper explores whether the principles of cognitive-load and multimedia theory are mediated by cognitive style, gender and prior knowledge. Ninety-one children aged 10 - 11 yrs (54 boys, 37 girls) were assigned to one of two presentation modes. In Condition 1 children were presented with diagrams supported by printed textual material, in Condition 2 the same diagrams were supported by narrated text. Condition 1 was designed in the conventional manner but Condition 2 was designed to adhere to cognitive load and multimedia theory. Following presentation children were asked a number of comprehension questions as an outcome measure requiring assimilation of information from both pictures and words. The Cognitive Style Analysis was administered to measure wholist-analytic style and verbal-imagery style. Results from national achievement tests were used as indicators of prior knowledge. Results indicate that outcome is differentiated by style, gender and prior knowledge not just instructional design.
\end{abstract}

Keywords: Cognitive style, gender, prior knowledge, cognitive load, multimedia theory 
What is the best way to present information? Should I use pictures and diagrams? Do I get better learning if I listen to text or read it? How should I organise information in order to ensure efficient learning? We ask many questions about how best to organise and present study media format to aid efficient learning, even more so with the popularity and flexibility of computer aided learning and hypermedia delivery modes (Chen \& Macredie, 2002). In order to answer these types of questions we can turn to contemporary cognitive learning theories such as cognitive load Theory (Sweller and Chandler, 1994) and the cognitive theory of multimedia learning (Mayer, 1999, 2001). However, few theories consider individual differences effectively. Clearly, the key to designing good instructional material is dependant upon having an accurate and informative model of the learner and how the learner learns best.

This paper considers how three important individual differences, namely, gender, prior knowledge and cognitive style, mediate learning for tasks designed using Mayer's theory of multimedia learning and cognitive load theory. Currently, both multimedia theory and cognitive load theory predict the learning outcome of multimedia materials by considering how the materials are designed and presented. However, little research has been conducted to ascertain how individual differences affect this outcome in light of the actual design of the learning task. Clearly, it is important for instructors to know whether the relevant design theory holds for all individuals and if not how the design should be modified to suit different learners. Therefore this study presents to two groups of learners the same multimedia learning materials. These are designed to be either of conventional design or of design that complies with multimedia theory and cognitive load theory. Learning outcomes are then examined to establish whether they are predicted purely by the material's design or whether individual characteristics such as gender, cognitive style and prior knowledge play a role.

\section{Cognitive Learning Theory}

There are a number of basic assumptions about the cognitive structures underpinning cognitive learning theory. These include firstly, that learning is an active process where learners attend to relevant incoming information, organise and select information and integrate it with prior knowledge (Mayer 1992; Mayer 2002). Secondly we assume that working memory is limited but long-term memory is 
extensive and thirdly that use of schemas enable information to be simplified and stored efficiently within long term memory. On this third point, this storage mechanism allows a schema the capability of being effectively utilised within the limited capacity of working memory with these schemas eventually becoming automatic and working via long term memory in parallel with the conscious processes of working memory (Sweller \& Chandler, 1994).

Working memory (Baddeley, 1974, 1986, 1999) can be described as a multifaceted mechanism with a number of elements running in parallel. It is argued that working memory constitutes a number of processors each with limited capacity. The visuo-spatial scratch pad manipulates visuo-spatial information, the phonological loop processes verbal material and the central executive controls and co-ordinates the other two.

\section{Cognitive Load Theory}

Cognitive load theory (Sweller, 1988) further states that information processed in working memory is split into two streams that are differentiated by modality therefore utilising the capacity of both the visuo-spatial scratch pad and the phonological loop. In essence, more cognitive capacity is available when information is split between the auditory system and the visual system. Sweller and Chandler (1994) argue that two important considerations for designing learning materials are whether the materials are presented in such a way as to cause split attention effects and whether they are presented so as to cause redundancy effects. Split attention effects are those effects caused by the material being split into a number of elements and requiring active integration in order for it to make sense. Quite often learning materials require learners to attend to both text and diagrammatic information in order to understand a particular concept and in this case the learners' attention is split between the two elements which require integration. A consequence of this split material is an increase in the cognitive load for the learner. An effective method of ameliorating the split attention effect is to present the text as narration simultaneously with the picture or diagrammatic information (Kalyuga, Chandler et al. 1999). The current study utilizes the redundancy effect in this way to produce an experimental condition that is of conventional design with attention split and a condition of good cognitive design without split attention where text is narrated. The redundancy effect is found when extra material is included that is not relevant to the concept being 
presented. This forces the learner to pay attention to extra material not necessary for the particular element being learned. Consequently, when redundant information interferes with relevant information in this way it also places a higher cognitive load on the learner.

\section{Multimedia Learning Theory}

Richard Mayer (2001, 1999), extends cognitive load theory and presents a theory of multimedia learning in terms of an information-processing model. This model is depicted in Fig 1. Mayer describes learning from multimedia materials as learning from any materials that combine more than one mode of delivery.

\section{(FIGURE 1 ABOUT HERE)}

Information enters sensory memory via either the eyes or ears allowing words to enter as sound (spoken) or visual stimuli (written). Pictures however can only enter as visual stimuli. Information enters sensory memory and if selected is transferred to working memory. Organization of sound or visual information takes place in working memory to create a model in a form that makes sense to the learner. This model (pictorial or verbal) is further integrated using prior knowledge. Clearly, words and pictures can be translated into different forms once selected in working memory; however this happens at a cost. Hence, pictures can be verbalised and textual information can be represented in pictorial form (shown by the arrows going between sounds and images in Fig 1). This model builds upon cognitive learning theory by assuming active construction of knowledge that is modified by prior knowledge and implies a cognitive system with limited capacity. Processing of information takes place within the constraints of sensory and working memory and takes advantage of dual processing theory as conceptualised by Baddeley (1999) and Clark and Paivio (1991) and each channel is mutually exclusive with limited capacity.

Mayer $(2001,1999)$ outlines seven guiding principles for presenting information in a multimedia format.

Multimedia Principle -there is better learning when learners receive words and corresponding pictures rather than words alone. This is clearly predicted by the 
model. The benefit of using both channels is that the capacity is increased and the learner receives the benefit of two models/representations.

Spatial Contiguity Principle-there is better learning when words and corresponding pictures are near rather than far from each other. The benefit of having words and pictures near to one another is that both representations can be held in working memory simultaneously and cognitive resources are reserved because the learner does not have to search for relevant material.

Coherence Principle-there is better learning when extraneous words and pictures are excluded rather than included. Extraneous words and pictures tend to compete with more relevant information for limited resources.

Modality Principle-there is better learning when words are presented as narration rather than in visual form. This is predicted by the model because both channels are used, one for the text and one for the picture rather than just the visual channel which would tend to be overloaded.

Redundancy Principle-there is better learning from animation and narration than from animation, narration, and on-screen text. On-screen text would tend to compete with animation for resources.

Temporal Contiguity Principle-there is better learning when corresponding words and pictures are presented simultaneously rather than successively. If words and pictures are processed in parallel they will be integrated into a more coherent model.

Individual Difference Principle-there are stronger effects for low rather than high prior knowledge learners and high rather than low spatial learners. This principle suggests that it is particularly important to implement good multimedia design for low knowledge and high spatial ability learners.

Mayer's model is limited in the extent to which it takes individual differences into consideration and this aspect requires further research to include other individual difference factors. Mayer (2001) states: "Some worthwhile venues for future research include the role of visual and verbal learning-style preferences." (p181) Hence, the aim of this research is to further delineate individual differences and their impact on multimedia design. 
Individual Differences and Multimedia Learning

Cognitive style

Cognitive style is seen as "an individual's preferred and habitual approach to organising and representing information" (Riding \& Rayner, 1998, p.11). The background to cognitive style has been extensively reviewed by Riding and Cheema (1991) and Riding and Rayner (1998). They conclude that the various style labels could be accommodated within two fundamental style dimensions-the wholistanalytic and the verbal-imagery-which may be described as:

(1) The wholist-analytic dimension of whether an individual tends to organise information into wholes or parts.

(2) The verbal-imagery dimension of whether an individual is inclined to represent information during thinking verbally or in mental pictures.

Cognitive style has been found to affect a wide range of behaviours, and this evidence for its construct validity has been considered by Riding and Rayner (1998; chapters 5-8). Further; style has been found to be independent of measured IQ (Riding \& Pearson 1994) and also of common personality measures (Riding \& Wigley 1997).

\section{The Nature of the Wholist-Analytic Dimension}

Riding and Rayner (1998) stated that the wholist-analytic style dimension was related to cognitive organisation. Rayner and Riding (1997) further expanded this by describing the wholist-analytic dimension as the way that individuals process or structure information.

Riding and Caine (1993) proposed the following description of how wholists and analytics view the world: Wholists are thought to have an overall perspective on things and are able to see the whole picture relatively easily when presented with information. Analytics see the information as a collection of parts rather than as a whole and may select certain parts to focus upon. Consequently, both styles have strengths and weaknesses. Wholists are strong in drawing together fragmented information to see the whole picture, whereas analytics are good at breaking information down into its integral parts and analysing each part separately. The wholist will have difficulty seeing beyond the whole and will find it difficult to separate information out into its integral parts and the different parts may blur into 
one. Analytics on the other hand will have difficulty drawing the parts together to see the whole picture and may concentrate on only one or two parts of the information at any one time.

\section{The Nature of the Verbal-Imagery Dimension}

Riding and Cheema (1991) hypothesised that this dimension was concerned with the way that information is represented. In other words concerned with whether information is represented by verbal constructs or images. Riding and Rayner (1998) suggested that individuals have the capacity to use either type of representation (verbal or visual), but generally they will have a preference for one or the other and will habitually use one type of representation.

Verbalisers and imagers differ (Riding \& Caine, 1993) with respect to the mode of presentation of information and the preferred contents of the material. Verbalisers prefer verbal, abstract material whereas imagers prefer concrete pictorial information that can be visualised. The implication of this is that if there is a mismatch between the information presented and the style of the individual then learning is reduced. Consequently, a simple analogy may be that verbalisers think in terms of words and imagers think in terms of pictures.

In the context of Mayer's multimedia model, imagers and verbalisers may be considered as synonymous with high and low spatial learners as is described within his seven principles. However, this comparison should be treated as theoretical as no empirical study has been carried out to determine the extent of the overlap (if any).

\section{Cognitive style and learning performance}

The effect of style on learning in terms of the structure, mode of presentation, and type of content of the material will be considered next. Learners who differ along the wholist-analytic dimension show differing learning outcomes according to the way that the information is structured. Analytics need to see how the information is integrated compared to wholists (Riding \& Grimley, 1999). With respect to the type of content, imagers recall highly visually descriptive text better than acoustically complex and unfamiliar text, while the reverse holds for verbalisers (Riding \& Calvey, 1981; Riding \& Dyer, 1980).

Two basic modes of presenting information are available these are the verbal 
and the pictorial. Taken overall, generally Imagers prefer and learn best from pictorial presentations, while verbalisers prefer and learn best from verbal presentations.

Riding and Read (1996) with 12-year-old children found that the tendency by imagers to use pictures, and verbalisers writing, increased with ability. There was evidence that lower ability children were more challenged by the expected format of the subject than were those of higher ability.

Sherry Chen and colleagues have carried out some work to explore learning from hypermedia with particular reference to the effect of cognitive style (Chen, 2002; Chen \& Macredie, 2002; Ford \& Chen, 2000; Ford \& Chen, 2001; Ghinea \& Chen, 2003). There is good evidence to suggest that cognitive style is an important variable to consider within learning models that deal with media mode and media structure. Chen's work concentrates mainly on media structure considering aspects such as navigation, nonlinear learning structures and learner control. Chuang (1999) however considered whether individual differences such as cognitive style (Field dependence/independence), gender and prior knowledge (maths) mediate learning outcome for different multimedia formats which included animation plus text, animation plus voice and animation, text plus voice. Results indicated that the field independent group and males scored higher for animation, text plus voice condition and those high in prior knowledge performed better on the animation plus text condition and the animation plus voice condition. No results are reported for interaction effects however the study does show some evidence of important individual difference effects related to mode of presentation.

\section{The Influence of Gender}

Riding and Grimley (1999) compared learning from computer-presented multimedia presentations of Picture and Speech (P-S) with Picture and Text $(\mathrm{P}-\mathrm{T})$ by 11-year-old children. They found gender differences for P-S and P-T in which there was a reversal with gender which was related to whether the styles were complementary, as with wholist-verbaliser and analytic-imager, or unitary as with analytic-verbaliser and wholist-imager. P-S involves two modes and two senses, 'look and listen' (two channels), while P-T is two modes but 'look' only, (a single channel). For the wholist-verbalisers and analytic-imagers (the complementary groups), males do better on P-S than on P-T, while this is reversed for females. For the unitary 
groups, the wholist-imagers and analytic-verbalisers, the tendency is the other way around with the male wholist-imagers better for P-T, and females better for P-S. Basically with males, complementary groups are best on a separation of the channels of pictures and words received aurally, while females are best on the single channel of picture and words. With the unitary groups the males are best on a single channel, while the females are superior on separate channels. Therefore evidence indicates an interaction of mode and style with gender, and while the precise nature of this is not yet clear it is likely to be of practical importance. Basically with males, complementary groups are best on a separation of the channels of pictures and words, while the females are best on the single channel of pictures and words. With the unitary groups, the males are best on a single channel, while the females are superior on separate channels. This hints at a fundamental gender difference in information processing which also involves style. Further, gender is an important consideration when investigating any individual difference factors related to learning as is evidenced by numerous reports of gender differences in learning worldwide.

\section{Prior Knowledge}

Prior knowledge is an important element in cognitive learning theory, with incoming information being integrated with the aid of prior knowledge, often referred to as long-term memory (Mayer, 2002). This element of knowledge construction is seen in Mayer's multimedia model (Mayer, 2001, 1999) and is also reflected in his seven principles with the suggestion that badly designed multimedia presentations will impact more on low prior knowledge (low knowledge) individuals than on high prior knowledge (high knowledge) individuals. This is supported by cognitive load theory with its emphasis on schema and automaticity (Sweller \& Chandler, 1994). As individuals develop greater knowledge structures their range of schemas become greater and their use of automatic processing increases. Consequently, design criteria become less important because individuals rely more on schemata and automaticity. Consequently, design effects can be observed for low knowledge individuals while there are no effects for high knowledge individuals (Kalyuga, Chandler \& Sweller, 1998, 2000). Finally, Riding and Read (1996) found that there was a tendency for verbalisers to use writing and imagers to use pictures/diagrams more so as knowledge level increased. Clearly, prior knowledge is an important factor to consider when 
describing learning outcome, but its exact nature is as yet unexplored in combination with other individual difference factors.

\section{Proposed Study and Aims}

This study seeks to establish whether cognitive style, gender and prior knowledge mediate the learning outcomes of multimedia tasks that have been designed to adhere to multimedia theory and cognitive load theory. Current literature suggests that a careful design of how the materials are presented will enhance learning performance, but little attention has been given to important individual differences such as those mentioned above. This issue will be addressed by presenting participants with learning materials designed according to the principles of multimedia theory and cognitive load theory in one condition compared to the same learning materials presented in the traditional manner in a second condition. Subsequently, participants of different genders, cognitive styles and prior knowledge groupings can then be compared according to their learning outcome across the two design groupings. Thus the study aims to identify whether multimedia theory and cognitive load theory can be applied generically across all learners or whether individual differences such as gender, cognitive style and prior knowledge mediate the predicted effects. In addition, if these effects are mediated by these individual differences attention will be directed to how these learning outcomes are mediated by individual difference factors in isolation and interaction. The design is further elaborated in the methods section. 
Method

Participants

Two urban state primary schools took part in this study. The participants were 91 children aged 10-11yrs (54 boys, 37 girls) comprising 61 children from school one and 30 children from school two. All children between the ages 10 and 11 yrs from school one were included in the study, with no exceptions, and all children from one particular 10-11 yr class from school two were included, with no exceptions, thus, giving a good spread of personalities and abilities.

\section{Design}

In Condition one the child reads the textual material (Appendix A) whilst referring to the pictorial information (Appendix B). In Condition two children were given a narrated version of the textual material whilst referring to the same pictorial information. Prior to their exposure to the textual or narrated information they were allowed to study the pictures for one minute in order to familiarize themselves with the pictures, which were common to both groupings, in order to avoid any confusion that may have been caused by the pictures themselves. According to cognitive load Theory (Sweller \& Chandler, 1994) Condition one imposes more cognitive load due to split attention effects than Condition two thus predicting poorer learning in Condition one. In Condition one participants were required to switch between reading and looking at the pictures in order to assimilate the information. However, for Condition two (narrated) children listen to information at the same time as looking at the pictures. Similarly, Mayer $(2001,1999)$ would predict via multimedia theory that Condition two would result in better learning than Condition one due to its use of dual channels and contiguity of information (Modality Principle and Temporal Contiguity Principle). Consequently, Condition one (written) is designed to be a poor multimedia model for instruction and Condition two (narrated) a good multimedia model for instruction.

\section{Materials}

The learning materials for this experiment were taken from a text that attempts to describe how things in the everyday world work (Macaulay D, 1988). A set of diagrams illustrating how mammoths could be used as sensors or detectors were taken from the book and all the writing explaining the pictures was removed including the 
titles. The only written information remaining on the picture/diagram was referential text labelling the separate picture groups e.g. Fig 1, Fig 2 etc (see Appendix B).

A sheet of written information about sensors and detectors was constructed (see Appendix A) by combining the original information from the text describing the illustrations and a passage containing technical information about real sensors and detectors. The passage was written in such a way as to be readily understood by 10 $11 \mathrm{yr}$. olds. This passage was then recorded on to an audiotape at 107wpm (normal speech rate being approximately $150 \mathrm{wpm}$.). The audio-taped passage was 3 minutes 17 seconds in length and contained 352 words. Six questions were devised to test knowledge and comprehension that could be assimilated from the text and pictures together. In attempting to answer these questions the learner needed to split their attention (Sweller \& Chandler 1994) between the two sources of information (textual and pictorial) in order to assimilate the information. The questions and answers that were used are shown below:

\section{How was the mammoth used to detect burglars?}

Answer: By putting its trunk under the mat for the burglar to tread on.

2. How was the mammoth used as a smoke detector?

Answer: By hooking its trunk to the ceiling so that it can smell any smoke.

\section{How was the mammoth used as a metal detector?}

Answer: The mammoth sits on the cases and anything that is not flattened is metal.

4. How was the mammoth used as a portable breathalyser?

Answer: A person is asked to breath into its trunk.

5. What does the mammoth have to do to make the ski lift rise?

Answer: Drink water.

6. The water is squeezed out of the mammoth when it reaches the ground, what should then happen to the lift?

Answer: It should return to the ground.

The Measurement of Cognitive Style

All participants were assessed individually for their cognitive style using the Cognitive Styles Analysis (Riding, 1991), which is a computer presented measure of cognitive style (see Riding \& Rayner, 1998 for more information). Children were tested in-groups of two to three using three personal computers with colour monitors. Scores on the verbal-imagery scale and wholist-analytic scale were obtained. 
The overall mean for the wholist-analytic dimension was 1.20 (SD.0.49) and the mean for the verbal-imagery dimension was 1.08 (SD. 0.17). A correlation between the ratios showed a non-significant correlation coefficient of $r=0.12$, thus indicating independent dimensions. A one-way analysis of variance of the two dimensions with gender as the independent variable gave no significance for either dimension, indicating that both dimensions were independent of gender. The two cognitive style dimensions were then divided into two divisions using a median split technique to give a balanced split between research conditions on the verbal-imagery data to enable equal numbers in each research condition. The resulting split as can be seen below is very close to the divisions suggested by Riding (2000) based on the secondary schools standardisation study (suggested as wholists 0-1.02; analytics 1.03 -4+; verbalisers $0-1.07$; imager $1.08-4+$ ).

The resulting divisions were: wholist-analytic dimension: wholist, $0.61-1.00$ (37); analytic. 1.01 - 2.92 (54): verbal-imagery dimension: verbaliser, 0.77 - 1.06 (46); imager, 1.07 - $1.71(45)$.

\section{Measurement of Prior Knowledge}

School children in England and Wales are required to sit tests of achievement at the end of Stage One (age 7), Two (age 11) and Three (age 14). These tests are called standard assessment tasks and assess knowledge and skills based on the national curriculum.

The children's raw scores for the maths and science standard assessment tasks (SAT) were used to calculate a prior knowledge grouping. A mean score for the combined maths and science SAT tests was calculated and a median split technique was used to ascertain a grouping. The resulting divisions were low $=7.75-19.99$, high $=20.00-32.75$. The overall mean for prior knowledge was 20.22 (SD. 6.26). A correlation between the prior knowledge means and the verbal-imagery and wholistanalytic ratios showed no significance between prior knowledge and either style dimension $(r=0.13, r=0.11)$ indicating independence.

\section{Procedure}

Children were allocated randomly to two groups where gender and cognitive style were counter balanced (Condition one and Condition two). 
Condition one children were told that they were going to see some pictures and they were to study them for one minute prior to being given some more information about the pictures. They were then told that they were going to be given some more information about the pictures and that they should study the pictures whilst reading the information by referring to the appropriate figure (labelled on the pictures and referred to in text) as they read through it. They were also told that they should only read through the information once and indicate the moment they had finished reading through it. Finally they were informed that they would be required to answer some questions about the information following their reading.

Condition one children were given similar instructions except that they would listen to some further information about the pictures (rather than read it). Similarly, in Condition two children were given one minute to study the pictures prior to hearing the recording of the text.

Although no time limit was given to Condition one (written group), times for reading were very similar to the times on task for Condition two (audio group), with children taking between 3 minutes and 3 minutes 30seconds (audio recording time $=3$ minutes 17 seconds).

Following the presentation subjects were given a piece of paper with spaces for them to answer the recall questions. The experimenter, who was male, then asked the questions orally allowing all children enough time to write down their answers. Children were tested in groups of three or four. 


\section{Results}

\section{Analysis}

An ANOVA (Analysis of Variance) was performed on the data and an alpha level of .05 was used for all statistical tests. Independent variables were gender (2), verbal-imagery style (2), wholist-analytic style (2), presentation condition (2) (information written or listened to) and prior knowledge level with the dependant variable being the number of questions answered correctly in the recall test.

In order to present the size of effect associated with the results, differences are also expressed as percentage increases or decreases between groups or across conditions. These percentage changes replace conventional effect size measures (such as Cohen's d) to allow the reader to put the changes into context.

\section{Overall Recall Effects}

Results reaching the $\mathrm{p}<.05$ significance level for the whole cohort (e.g. for both conditions together) are presented in this section. Two main effects were observed. Firstly, prior knowledge $(F(1,28)=7.88, p<.01)$. Secondly, wholistanalytic style $(F(1,28)=5.17, p=.03)$. The main effect of prior knowledge indicated that those in the high knowledge group answered more questions correctly than children in the low knowledge group $[\mathrm{M}=2.28, \mathrm{SD}, 1.25, \mathrm{M}=3.83, \mathrm{SD}, 1.56]$. This trend is not surprising and therefore will not be discussed any further.

The main effect of wholist-analytic style showed that wholists tended to answer more recall questions correctly overall compared to analytics $[\mathrm{M}=3.53, \mathrm{SD}=$ $1.59, \mathrm{M}=3.10, \mathrm{SD}=1.59]$. A two-way interaction of gender by wholist-analytic style $(F(1,28)=4.97, p=.03)$ is shown in Table 1 below.

\section{(TABLE 1 ABOUT HERE)}

Results shown in Table 1 indicated that female analytics perform particularly badly on the overall task. The other three groupings were performing at similar levels to each other with their mean scores well above that of female analytics.

Table 2 shows a three-way interaction between wholist-analytic style, verbalimagery style and gender $(F(1,28)=6.37, p=.02)$. All style groupings except wholist-verbalisers showed differences across genders. 


\section{Design Effects}

Results that showed effects between the two different designs (i.e. across Condition one -written and Condition two - narrated) are now considered. If the overall difference in recall is examined between conditions one and Condition two little difference is observed (percentage difference $=+1 \%$ ). However, if the relative performance of different groups of individuals according to their gender, prior knowledge and cognitive style are examined a number of differences are seen.

Table 3 below shows a three-way interaction of wholist-analytic style by gender by presentation condition $(F(1,28)=9.20, p<.01)$. Recall improved from Condition one to Condition two for male wholists and female analytics. Male analytics and female wholists scored lower in recall between Condition one and Condition two.

\section{(TABLE 3 ABOUT HERE)}

Examination of Table 4 shows a similar interaction of verbal-imagery by gender by condition $(F(1,28)=7.27, p=.01)$. Male imagers and female verbalisers complied with what would be expected from cognitive load theory and the multimedia model by scoring higher in Condition two than Condition one. However, learning decreased from Condition one to Condition two for male verbalisers and female imagers.

\section{(TABLE 4 ABOUT HERE)}

An interaction between gender, presentation condition and prior knowledge $(F(1,28)=7.58, p=.01)$ is illustrated in Table 5 below. Table 5 shows that high knowledge males scored higher than all other groupings in Condition one (written). Improvements from Condition one to Condition two for these other groupings indicated that improvements in outcome were significant, ranging from a $36 \%$ improvement to a $55 \%$ improvement.

\section{(TABLE 5 ABOUT HERE)}

Table 6 below shows the three-way interaction between prior knowledge, verbal-imagery style and presentation condition $(F(1,28)=7.97, p=.01)$. Low 
knowledge verbalisers scored significantly higher in condition 2 than condition 1 . However, other groupings only scored slightly higher or stayed the same from Condition one to Condition two.

(TABLE 6 ABOUT HERE)

\section{Discussion}

In terms of overall performance the data seems to indicate that the characteristics of the wholist seem to be better suited for this particular task and material. This may be due to wholists being better at seeing the bigger picture (Riding \& Cheema, 1991; Riding \& Rayner, 1998) (the whole view) and thus better able to integrate the textual and pictorial information required to answer the comprehension style recall questions. Analytics would be challenged when assimilating information from text and pictures, whether of good design or poor design, which was an essential part of this task for the children. It also appears that female analytics are at a disadvantage in terms of this particular learning task. This may reflect the difficulty females have in assimilating information when relying on an analytic style as opposed to males who perform relatively well with an analytic style. Evidence for these reversal type effects between different genders but similar styles is evident in other studies involving mode of presentation (Riding \& Grimley, 1999) and further exploration into these types of effect are warranted. In addition, for this particular task the wholist-analytic style and verbal-imagery style in combination appear to interact with gender to show differing information processing characteristics for males and females. It appears that males and females show different information processing characteristics in combination with cognitive style.

An examination of the relative performance of different groups of individuals according to their gender, prior knowledge and cognitive style highlights a number of differences in outcome across the different design conditions. It appears that cognitive load and multimedia design effectiveness depend upon the characteristics of the individual learner. Presentation Condition two gives good outcome results for male wholists, female analytics, male imagers and female verbalisers but is actually detrimental to the opposite style-gender groupings. As previously indicated by Riding and Grimley (1999) a fundamental gender difference in information processing for particular presentation modes involving style is evident. Riding and Rayner (1998) 
make comparisons between wholists and imagers and suggest that they are both style dimensions that have characteristics giving individuals of these style groupings the benefit of being able to view information from the wholistic/overview perspective. Additionally, comparisons can also be made between verbalisers and analytics in that these two styles have an element of both being analytic types of style where information tends to be viewed in chunks/pieces rather than as a whole. This implies that the way information is represented by the individual will mediate the processing strategies, and thus the outcome of the learning task. The task of learners in this study was very much oriented around the assimilation and recall of distantly positioned information. Consequently it is possible that this element of the information processing procedure was a factor in influencing the outcome for different individuals. Further studies with different task emphasis are needed to explore this idea further.

Results also show an interaction between prior knowledge and gender with high knowledge males performing better under Condition one, contrary to what would be expected given the design characteristics. Previous studies (Mayer, 2001; Kalyuga et al, 1998, 2000) indicated that low knowledge individuals get greater benefits than high knowledge individuals from well designed multimedia presentations. These high knowledge individuals in some cases showed the reverse effect with performance being better for traditionally designed materials. This finding is also supported in this study. There is also evidence to suggest that gender is an important factor to consider. The current study implies that the high-low knowledge rule may only apply to males. Females appear to require well designed materials for improved learning outcomes whether prior knowledge is high or low.

Application of good design according to cognitive load and multimedia theories increased learning outcomes for low knowledge verbalisers by a massive 83\%. Therefore this finding supports Mayer's multimedia model with low knowledge and low imagery individuals gaining the most from designing the presentation to comply with this model. Mayer (2001) goes some way to describing how individual differences might interact with the model proposed, however, it is clear from the results of this study that further work is needed and elements of cognitive style and gender need to be included in order to develop a fuller and more comprehensive model. 
Further studies in this area should perhaps attempt to isolate particular principles identified by Mayer and ascertain how outcome is mediated by particular individual differences. It is recognised that in this particular study the outcome measure was recall only. In essence, it would have benefited from other outcome measures such as knowledge transfer measures (Mayer, 2001). In addition, the prior knowledge measurement used in this study was a student's result in certain standardised assessment tests. These knowledge indicators may in actual fact not be related to the domain that is being tested in the learning exercise. Therefore, it may be desirable to find a way of assessing knowledge that is related to the learning exercise rather than this general way of defining prior knowledge. On the other hand a general measure of prior knowledge may well be desirable as this is readily available to most educators. 


\section{Conclusion}

This study set out to explore whether the multimedia and cognitive load models could be used generically across all individuals or whether such models needed to be modified to suit individual needs. This study supports the idea that cognitive style, gender and prior knowledge mediate learning outcome as predicted by these two models. In particular there appears to be a mediating effect caused by an interaction with gender and both the verbal-imagery dimension and the wholistanalytic dimension. Both of these effects may actually be synonymous with a particular characteristic of the way an individual organises or represents the material and is gender specific. Models such as Mayer's multimedia model and cognitive load clearly boost our capability to design more effective learning materials, however, any model designed to improve learning needs to take account of individual differences, as ultimately this is what learning is about. In particular, given the current climate of differential educational outcomes between boys and girls it would be desirable to learn more about gender interactions and their effects on information processing.

Mayer (2001) previously indicated that spatial ability and prior knowledge are important factors in any model of multimedia design for learning and that they should be explored further. Research by Riding and Grimley (1999) also indicated that gender in interaction with cognitive style might be important in mediating any information-processing model of learning. The study presented here suggests that further work in this area is indeed warranted. It is evident that all of these factors are important; however the exact nature of these interactions is still uncertain. Perhaps in the first instance there is a clear need to attempt to replicate these findings. In addition, some methodological flaws are evident in that it was difficult to ascribe the exact time that children spent on the textual version of the task, although timings did indicate a similar time to the audio version. Therefore there is a need to make sure that reading time is the same for the narrated version and written version, this may be possible by presenting the material via computer. 


\section{References}

Baddeley, A. (1986). Working Memory. New York: Oxford University Press.

Baddeley, A. (1990). Human memory: Theory and practice. New York:

Lawrence Erlbaum Associates.

Baddeley, A. (1999). Essentials of human memory. Hove: Psychology Press.

Baddeley, A., \& Hitch, G. J. (1974). Working memory. In Recent advances in learning and motivation Vol. VIII (G. Bower, ed.) pp 47-49. Academic Press, New York.

Chen, S. Y. (2002). A cognitive model for non-linear learning in hypermedia programmes. British Journal of Educational Technology, 33(4), 449-460.

Chen, S. Y., \& Macredie, R. D. (2002). Cognitive Styles and hypermedia navigation: Development of a learning model. Journal of the American Society for Information Science and Technology, 53(1), 3-15.

Chuang, Y. R. (1999). Teaching in a multimedia computer environment: A study of effects of learning style, gender, and math achievement. Interactive Multimedia Electronic Journal of Computer-Enhanced Learning, 1(10).

Retrieved April 4, 2006, from http://imej.wfu.edu./articles/1999/1/10/index/asp

Clark, J. M., \& Paivio, A. (1991). Dual coding theory and education. Educational Psychology Review, 3(3), 149-210.

Ford, N., \& Chen, S. Y. (2000). Individual differences, hypermedia navigation, and learning: An empirical study. Journal of Educational Multimedia and Hypermedia, 9(4), 281-311.

Ford, N., \& Chen, S. Y. (2001). Matching/mismatching revisited: An empirical study of learning and teaching styles. British Journal of Educational Technology, 32(1), 5-22.

Ghinea, G., \& Chen, S. Y. (2003). The impact of cognitive styles on perceptual distributed media quality. British Journal of Educational Technology,. 34(4), 393-406.

Kalyuga, S., Chandler, P., \& Sweller, J. (1998). Levels of expertise and instructional design. Human Factors, 40(1), 1-17.

Kalyuga, S., Chandler, P., \& Sweller, J. (1999). Managing split-attention and redundancy in multimedia instruction. Cognitive Psychology, 13, 351-371. 
Kalyuga, S., Chandler, P., \& Sweller, J. (2000). Incorporating learner experience into the design of multimedia instruction. Journal of Educational Psychology, 92(1), 126-136.

Mayer, R. E. (1992). Cognition and instruction: Their historic meeting within educational psychology. Educational Psychology, 84(4), 405-412.

Mayer, R. E. (1999). Research-based principles for the design of instructional messages: The case of multimedia explanations. Document Design, 2(1), $7-20$.

Mayer, R. E. (2001). Multimedia Learning. New York: Cambridge University Press.

Mayer, R. E. (2002). Research-based principles for the design of instruction messages. Document Design, 1(1), 2-14.

Rayner, S., \& Riding, R. J. (1997). Towards a categorisation of cognitive styles and learning styles. Educational Psychology, 17(1 \& 2), 5-27.

Riding, R. J. (1991). Cognitive styles analysis. Birmingham: Learning and Training Technology.

Riding, R. J. (1996). Learning styles and technology based training. Sheffield: DfEE.

Riding, R. J. (2000). CSA - Research Applications. Birmingham: Learning and Training Technology.

Riding, R. J., \& Agrell, T. (1997). The effect of cognitive style and cognitive skills on school subject performance. Educational Studies, 23, 311-323.

Riding, R. J., \& Ashmore, J. (1980). Verbaliser-imager learning style and children's recall of information presented in pictorial versus written form. Educational Psychology, 6, 141-145.

Riding, R. J., \& Caine, T. (1993). Cognitive style and GCSE performance in mathematics, English language and French. Educational Psychology, 13, 59-67.

Riding, R. J., \& Calvey, I. (1981). The assessment of verbal-imagery learning styles and their effect on the recall of concrete and abstract prose passages by eleven year old children. British Journal of Psychology, 72, 59-64.

Riding, R. J., \& Cheema, I. (1991). Cognitive styles - An overview and integration. Educational Psychology, 11, 193-215. 
Riding, R. J., \& Douglas, G. (1993). The effect of cognitive style and mode of presentation on learning performance. British Journal of Educational Psychology, 63, 297-307.

Riding, R. J., \& Dyer, V. A. (1980). The relationship between extraversion and verbal-imagery learning style in 12-year-old children. Personality and Individual Differences, 1, 273-279.

Riding, R. J., \& Grimley, M. (1999). Cognitive style, gender and learning from multimedia materials in 11-year-old children. British Journal of Educational Psychology, 30(1), 43-56.

Riding, R. J., \& Pearson, F. (1994). The relationship between cognitive style and intelligence. Educational Psychology, 14, 413-425.

Riding, R. J., \& Rayner, S. (1998). Cognitive style and learning strategies. London: David Fulton Publishers.

Riding, R. J., \& Read, G. (1996). Cognitive style and pupil learning preferences. Educational Psychology, 16, 81-106.

Riding, R. J., \& Watts, M. (1997). The effect of cognitive style on the preferred format of instructional material. Educational Psychology, 17, 179-183.

Riding, R. J., \& Wigley, S. (1997). The relationship between cognitive style and personality in further education students. Personality and Individual Differences,_23, 379-389.

Sweller, J. (1988). Cognitive load during problem solving: Effects on learning. Cognitive Science, 12, 257-285.

Sweller, J., \& Chandler, P. (1994). Why some material is difficult to learn. Cognition and Instruction, 12(3), 185-233. 


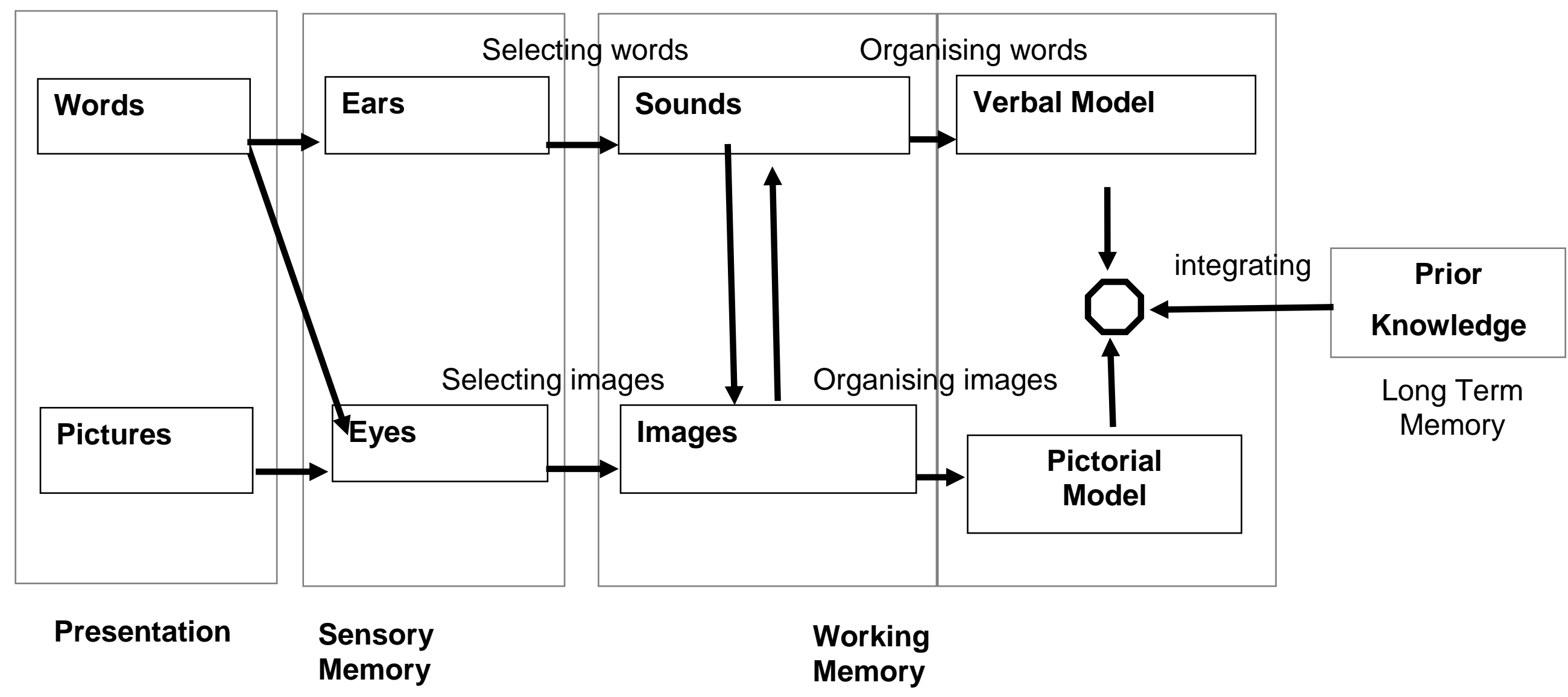

Figure 1 Diagram Depicting Mayer's Multimedia Model. Adapted from Mayer (2001). 
Table 1 Mean Score, Standard Deviation (in brackets) and Percentage Change for the two-way Interaction of Gender by Wholist-Analytic Style

\begin{tabular}{l|ccc}
\hline & Mean scores for question recall (with SD in brackets) & Percentage change \\
\hline \multirow{3}{*}{ Male } & Wholist & Analytic & \\
Female & $3.38(1.66)$ & $3.72(1.51)$ & $+10 \%$ \\
percentage change & $3.83(1.47)$ & $2.30(1.33)$ & $-39 \%$ \\
\hline
\end{tabular}


Table 2 Mean Score, Standard Deviation (in brackets) and Percentage Change for the Gender by Wholist-Analytic by Verbal-Imagery Interaction

\begin{tabular}{lcccc}
\hline \multicolumn{5}{c}{ Mean Scores for Question Recall (with SD in Brackets) } \\
\hline \multirow{4}{*}{ Male } & Wholist-Verbaliser & Wholist-Imager & Analytic-Verbaliser & Analytic-Imager \\
Female & $3.82(1.60)$ & $3.0(1.68)$ & $4.0(1.65)$ & $3.43(1.34)$ \\
Percentage & $3.86(1.35)$ & $3.8(1.79)$ & $2.3(1.34)$ & $2.31(1.38)$ \\
change & $+1 \%$ & $+26 \%$ & $-42 \%$ & $-32 \%$ \\
\hline
\end{tabular}


Table 3 Showing Means, Standard Deviations (in brackets) and Percentage Change for the Gender by Wholist-Analytic Style by Presentation Condition Interaction

\begin{tabular}{l|cccccc}
\hline & Cond 1 & Cond 2 & \multicolumn{5}{c}{ Cond 1 } & Cond 2 & \\
\hline & Wholist & Wholist & $\begin{array}{c}\text { Percentage } \\
\text { Change }\end{array}$ & Analytic & Analytic & Percentage \\
& & & & & Change \\
Male & $2.92(1.98)$ & $3.83(1.19)$ & $+31 \%$ & $4.06(1.44)$ & $3.31(1.55)$ & $-18 \%$ \\
Female & $4.20(1.48)$ & $3.57(1.51)$ & $-15 \%$ & $2.08(1.51)$ & $2.55(1.13)$ & $+22 \%$ \\
\hline
\end{tabular}


Table 4 Showing Means, Standard Deviations (in brackets) and Percentage Change for the Gender by Verbal-Imagery Style by Presentation Condition Interaction

\begin{tabular}{l|cccccc}
\hline & Cond 1 & Cond 2 & & Cond 1 & Cond 2 & \\
\hline & Verbaliser & Verbaliser & $\begin{array}{c}\text { Percentage } \\
\text { Change }\end{array}$ & Imager & Imager & $\begin{array}{c}\text { Percentage } \\
\text { Change }\end{array}$ \\
Male & $4.00(1.77)$ & $3.82(1.40)$ & $-4 \%$ & $3.08(1.66)$ & $3.36(1.39)$ & $+9 \%$ \\
Female & $2.50(1.60)$ & $3.33(1.41)$ & $+33 \%$ & $2.89(1.96)$ & $2.56(1.24)$ & $-11 \%$ \\
\hline
\end{tabular}


Table 5 Showing Means, Standard Deviation (in brackets) and Percentage Change for the Gender by Prior Knowledge by Presentation Condition Interaction

\begin{tabular}{l|cccccc}
\hline & Cond 1 & Cond 2 & & Cond 1 & Cond 2 & \\
\hline & High & High & Percentage & Low & Low & Percentage \\
& Knowledge & Knowledge & Change & Knowledge & Knowledge & Change \\
Male & $4.75(1.58)$ & $3.71(1.38)$ & $-21 \%$ & $2.13(1.13)$ & $2.90(1.45)$ & $+36 \%$ \\
Female & $2.75(1.49)$ & $4.17(1.17)$ & $+51 \%$ & $1.40(0.55)$ & $2.17(1.17)$ & $+55 \%$ \\
\hline
\end{tabular}


Table 6 Showing Mean, Standard Deviation (in brackets) and Percentage Change for the Prior Knowledge by Verbal-Imagery Style by Presentation Condition Interaction

\begin{tabular}{l|ccllll}
\hline & Cond 1 & Cond 2 & \multicolumn{3}{c}{ Cond 1 } & Cond 2 \\
& Verbaliser & Verbaliser & $\begin{array}{l}\text { Percentage } \\
\text { Change }\end{array}$ & Imager & Imager & Percentage \\
& & & & & Change \\
High & $4.22(1.72)$ & $4.33(1.21)$ & $+2 \%$ & $3.14(1.86)$ & $3.57(1.27)$ & $+13 \%$ \\
Knowledge & & & & & & \\
Low & $1.71(1.11)$ & $3.13(1.46)$ & $+83 \%$ & $2.00(0.89)$ & $2.13(1.13)$ & $+6 \%$ \\
Knowledge & & & & & & \\
\hline
\end{tabular}




\section{Appendix A}

\section{Appendix A showing the written information about sensors and detectors}

Sensors and Detectors

This passage tells you something about how modern sensors and detectors work, you can see in the pictures how ancient sensors and detectors worked using the woolly mammoth.

Sensors and detectors are instruments that are used to detect the presence of something and quite often to measure it. Burglar alarms sense the direct evidence of intruders such as the tell-tale tread of burglars, smoke alarms detect the presence of smoke particles in the air.

Fig 1 shows the use of the woolly mammoth for detecting unwanted visitors. Mammoths are highly sensitive creatures. Their physical sensitivity can be used in numerous ways.

Fig 2 shows how the trunk of a sleeping mammoth can be used as a smoke detector. The plants obscure the creatures bulk and also provide it with the occasional snack.

Other sensors and detectors use penetrating rays or magnetic fields to find objects that can not be seen. Measuring instruments like radar speed traps are used by the police and are examples of sensors and detectors that react to something specific and then record its quantity.

It can be seen in Fig 3,4 and 5 how a highly trained mammoth can be used as a metal detector. One piece of luggage has been tested and there is no question about the location of bulky items, there's a good chance that they are metal. Another type of measuring instrument is the breathalyser used by the police to detect alcohol on someone's breath.

In fig 6 and fig 7 the mammoths trunk is employed as a highly sensitive mobile breathalyser.

Sensors and detectors are also very important in automatic machines. Many machines, for example the autopilot of an aircraft, use feedback. This means that the sensor actually measures the machine's performance and then feeds back the results to control the power output. By sensing their own performance, automatic machines keep within set limits. The mammoth powered weight sensing ski lift is a simple automatic machine.

Fig 8 shows the automated ski lift.

Fig 9 shows the specially designed squeezer which forces the water out making the lift return to the ground. 
Appendix B

Appendix B Pictorial information for the sensors and detectors learning task

Submitted as TIFF files 